\title{
Pancreatogastrostomy - History and Current Evidence
}

\author{
Louisa Bolm¹ , Ulrich F Wellner ${ }^{1}$, Yogesh K Vashist ${ }^{2}$, Tobias Keck ${ }^{1}$
}

'Clinic of Surgery, UKSH Campus Lübeck, Germany

${ }^{2}$ Department of Surgery, University Clinic Hamburg Eppendorf, Germany

\author{
Corresponding author: \\ Ulrich F. Wellner \\ Surgery Assistant \\ Clinic for Surgery, UKSH Campus Lübeck \\ Ratzeburger Allee 160, 23538 Lübeck, \\ Germany \\ E-mail: ulrich.wellner@uksh.de
}

\section{ABSTRACT}

Two anastomotic techniques are available for reconstruction after pancreatoduodenectomy: pancreatojejunostomy, which is the traditional and most widely used technique, and pancreatogastrostomy. The latter was introduced into clinical practice more than 50 years ago, and has recently received increasing attention due to favorable outcome when compared to pancreatojejunostomy in randomized controlled trials. We briefly review the history, current evidence and emerging applications of pancreatogastrostomy.

Key words: pancreatoduodenectomy, pancreatogastrostomy, outcomes

\section{HISTORICAL PERSPECTIVE}

It is hardly known that the history of pancreatogastrostomy (PG) dates back to the very beginning of pancreatic surgery. Already Walter Kausch, in his 1912 publication of the first successful pancreatoduodenectomy (PD) performed in Berlin in 1909 (1), discussed the possibility of reconstruction by anastomosis of the pancreatic remnant to the stomach. In his opinion this reconstruction technique was "unsafe and dangerous".

Following experimental studies by Tripodi and Sherwin published in 1934 (2), Waugh and Clagett (3) in 1946 were the first to publish the clinical application of pancreatogastric anastomosis in PD for cancer. The method was adopted or reintroduced by several authorities around the world and reported as cases in the 1950s (4-6) and small series since the 1970s (7).

\section{THEORETICAL AND TECHNICAL ASPECTS OF PANCREATOGASTROSTOMY}

Theoretical aspects that could PG make more secure in comparison to the traditional pancreatojejunostomy (PJ) have been discussed already by the early 
pancreatic surgeons (8). First, the gastric wall is in direct anatomical proximity to the pancreas. It usually provides a thick and strong barrier for a deep invagination of the pancreatic remnant. In addition, there is a potential to prevent the activation of pancreatic enzymes by the acidic gastric milieu and lack of intestinal enterokinase and bile. On the other hand, gastric acid might be neutralized to some degree by the alkaline pancreatic juice to prevent ulceration at the gastroenterostomy.

Regarding technical details, in order to achieve invagination of the pancreatic remnant, adequate and usually more extensive mobilization than with pancreatjejunostomy is necessary. This can be challenging in the case of a fibrotic pancreas with heavy adhesion to the retroperitoneal tissue, as for example found in chronic pancreatitis.

Various techniques of PG have been described (9-18): single-layer, double layer, binding technique, with duct-to-mucosa anastomosis, mattress sutures, pancreatic duct stenting, gastric partitioning, additional anterior gastrotomy, and reinforcement by biodegradable meshes, glue, falciform ligament and omental flaps. There is however no meaningful data to compare these different techniques among each other. Semantically, pancreaticogastrostomy refers to techniques involving duct-to-mucosa anastomosis, while pancreatogastrostomy means that duct-to-mucosa suture is omitted (19). For simplicity the word pancreatogastrostomy is used for all techniques here.

\section{RETROSPECTIVE STUDIES COMPARING PANCREATOGASTROSTOMY AND PANCREATOJEJUNOSTOMY IN PANCREATO- DUODENECTOMY}

The first metaanalysis of PD comparing PG with pancreatojejunostomy (PJ) appeared in 1991 (20) and incorporated over 2600 patients out of over 8000 PDs from retrospective data in the available literature. The authors found a reduced morbidity with PG compared to different types of PJ. The next large metaanalysis was performed by Wente et al in 2007 (21), when data from three randomized controlled trials (RCT) had already become available. Analysis of the contemporary retrospective data from 13 comparative studies published between 1990 and 2004 disclosed a clear superiority of PG over PJ in terms of reduced rate of postoperative pancreatic fistula (POPF), bile leaks, intraabdominal fluid collections, overall complications and even mortality.

\section{RANDOMIZED TRIALS COMPARING PANCREATOGASTROSTOMY AND PANCREATOJEJUNOSTOMY IN PANCREATODUODENECTOMY}

The first RCT comparing PG and PJ was reported from Baltimore by Yeo et al in 1995 (22) and did not detect a difference regarding POPF rate and mortality. It took 10 more years until the first European RCTs were published. Bassi et al from Verona, Italy (23) randomized only high-risk patients with a soft pancreas and found no difference in POPF rates, but demonstrated significantly less multiple complications, intraabdominal fluid collections and bile leaks with PG. Duffas et al (24) performed the first multicenter RCT in France and did not observe significant differences in outcome after PG or PJ.

A special technique of PG with pancreatic partitioning was evaluated in a RCT by Fernandez-Cruz and colleges in Barcelona, Spain (10). They demonstrated a significantly lower rate of clinically relevant POPF with PG, now reported according to the 2004 International Study Group for Pancreatic Surgery (ISGPS) classification (25). Furthermore, overall complication rate, intraabominal fluid collections and delayed gastric emptying were significantly reduced after PG with gastric partitioning.

The next RCT was reported by Wellner et al (26) from Freiburg, Germany in 2012 but did not reveal differences regarding perioperative outcome. A twocenter RCT was published by Figueras and coworkers (27) from Girona and Valencia, Spain in 2013 and demonstrated a significantly reduced POPF and readmission rate. The most recent single-center RCT reported in 2014 by El-Nakeeb et al (28) from Mansoura, Egypt compared isolated Roux-Y PJ to PG and did not disclose singnificant differences regarding perioperative outcome.

While the aforementioned trials had relatively low case numbers ( $n=90-151)$, a recent multicenter RCT from Belgium (29) successfully assessed 329 patients for comparison of PG and PJ in an intention to treat (ITT) analysis. The results show a significant reduction of clinically relevant POPF and complications of Clavien-Dino grade $\geq 3$ a. The results of another large multicenter RCT from Germany (RECOPANC) have recently been published by Keck et al (30). In ITT analysis of 320 patients, there was no significant difference in pancreatic fistula rate or other complications except an increased rate of low-grade postpancreatectomy hemorrhage with PG. The relevant factors influencing POPF rate were pancreatic texture and surgeon case 
load. Low-volume surgeons had an about $50 \%$ reduction in POPF rate with PG compared to PJ, but due to limited case number this subgroup analysis was not statistically significant. In long-term follow-up, there was no difference in pancreatic function. The authors concluded that PG is a safe and probably technically less demanding anastomosis, especially for high-risk patients with a soft pancreas.

The current literature provides many metaanalyses comparing PG and PJ. No metaanalysis has yet included all current RCTs. In brief, eight metaanalyses published in 2014 (31-38) agree that PG is superior to PJ in terms of reduced rate of POPF, intraabdominal fluid collections and biliary leaks.

\section{SPECIFIC ASPECTS OF COMPLICATION MANAGEMENT AND PANCREATOGASTROSTOMY}

Postpancreatectomy hemorrhage (PPH) is classified as intraluminal and extralumunal according to the ISGPS (39). An increased rate of intraluminal PPH has been observed with PG compared to PJ $(17,40,41)$, which was attributable to bleeding from the PG anastomosis site and pancreatic cut surface. The theoretical advantage that anastomotic bleeding can be managed by endoscopic intervention in PG (42) could not be confirmed in a recent large retrospective series (43).

Late extraluminal bleeding is a grave complication after PD. Reduced mortality has been observed with PG compared to PJ in critical conditions like extraluminal bleeding and completion pancreatectomy (41). An advantage of PG is that in case of completion pancreatectomy, the hepaticojejunostomy loop is not affected. Furthermore, PG has been proposed as a salvage procedure to avoid completion pancreatectomy for severe POPF after PJ $(44,45)$.

\section{PANCREATIC FUNCTION AFTER PANCREATOGASTROSTOMY}

A commonly encountered prejudice is that pancreatic function is worse after PG than with PJ. Several investigators studied pancreatic duct morphology and exocrine function after PG and observed a high rate of pancreatic duct dilatation and exocrine insufficiency (46-52). This is however a common finding after PD in general $(53,54)$.

Data from comparative retrospective studies is based on relatively small case numbers and yields conflicting results. Six studies demonstrate no significant difference between PG and PJ (55-60), four studies report reduced pancreatic function with
PG compared to PJ (61-64), one study shows improved fat absorbtion with PG (65) and another improved gastrointestinal motility (66) with PG versus PJ.

An early small RCT from Japan disclosed equal pancreatic function after PG and PJ (67). The recent RCT performed by Figueras et al (27) evaluated endocrine and exocrine pancreatic function 6 months after the operation, and found a significantly better exocrine function with PG compared to PJ. The Egyptian RCT (28) however demonstrates reduced pancreatic exocrine and endocrine function with PG compared with isolated Roux-Y PJ. Probably the best current evidence comes from the German multicenter RECOPANC trial. In follow-up after one year, no relevant differences were detected regarding quality of life and pancreatic endocrine and exocrine function.

In summary, data on pancreatic function after PG as compared to PJ remains inconsistent and further prospective evaluation is necessary.

\section{NOVEL AND RARE INDICATIONS FOR PG}

\section{Endoscopic surveillance after resection of cystic neoplasms}

There is a risk of recurrence after resection of intraductal papillary mucinous neoplasms (IPMN). Few authors have advocated PG in these patients to facilitate postoperative surveillance by endoscopy (68-70). There is however no large-scale data to support this assumption.

\section{$P G$ in central pancreatectomy}

Central pancreatectomy (CPE) is a rarely performed procedure and current literature yields about 1000 published cases since the 1980s (71). It is experiencing increased interest in recent years as a means of parenchyma-sparing resection of borderline and preneoplastic lesions like cystic neoplasms of the pancreas, which are increasingly diagnosed and resected. PG has gained popularity in laparoscopic central pancreatectomy, probably because it is technically less demanding than PJ and offers a safe anastomosis as well: A recent survey of 51 published laparoscopic CPE shows that in over $60 \%$, PG was used for reconstruction (72).

\section{$P G$ in distal pancreatectomy}

POPF remains a problem after DPE and a recent European multicenter RCT failed to demonstrate a reduction of POPF with stapler closure of the 
pancreatic stump (73). Pancreatogastrostomy for drainage of the pancreatic stump after distal pancreatectomy has been applied by Japanese surgeons and reported to yield favorable outcomes including reduced POPF and POPF-related complications as well as cost $(74,75)$. There is even an ongoing RCT comparing PG versus stump closure during DPE in Japan (UMIN000007426).

\section{Pancreatogastrostomy in surgical education}

Last but not least, PG offers a safe and relatively easy to learn anastomotic technique suited for pancreatic surgery residents in training (76).

\section{CONCLUSIONS}

More than 100 years after the first PD and more than 50 years after its first clinical application, PG emerge as a valuable option for reconstruction in PD and CPE due to several reasons. Current first level evidence suggests a reduction of pancreatic fistula and other complications with PG compared to PJ in PD. Pancreatic function after PG seems to be equal to $\mathrm{PJ}$, although more data is needed to confirm this assumption. It remains unclear if there is a benefit from the various published technical modifications. PG is a relatively easy to perform but safe anastomotic technique for reconstruction after PD and possibly also for central and distal pancreatectomy. More data is needed to evaluate its role in minimal invasive procedures, central and distal pancreatectomy, as well as in surgical education.

\section{REFERENCES}

1. Kausch. Das Carcinom der Papilla Duodeni und seine radikale Entfernung. Beitr Z Clin Chir. 1912;78:439-86.

2. Tripodi AM, Sherwin CF. Experimental transplantation of the pancreas into the stomach. Arch Surg. 1934;28:345-356.

3. Waugh JM, Clagett OT. Resection of the duodenum and head of the pancreas for carcinoma; an analysis of thirty cases. Surgery. 1946 Aug;20: 224-32.

4. Dill-Russell AS. Pancreaticogastrostomy. Lancet. 1952 Mar 22; 1(6708): 589-90.

5. Ingebrigtsen R, Langfeldt E. Pancreaticogastrostomy. Lancet. 1952 Aug 9; 2(6728):270-1.

6. Wells C, Shepherd JA, Gibbon N. Pancreaticogastrostomy. Lancet. 1952 Mar 22;1(6708):588-9.

7. Shinchi H, Takao S, Maenohara S, Aikou T. Gastric acidity following pancreaticogastrostomy with pylorus-preserving pancreaticoduodenectomy. World J Surg. 2000 Jan;24(1):86-90; discussion 90-1.

8. Strauch GO. The use of pancreatogastrostomy after blunt traumatic pancreatic transection: a complete and efficient operation. Ann Surg. 1972 Jul;176(1):16-8.

9. Bartsch DK, Langer P, Kanngießer V, Fendrich V, Dietzel K. A simple and safe anastomosis for pancreatogastrostomy using one binding purse-string and two transfixing mattress sutures. Int J Surg Oncol. 2012:2012:718637.

10. Fernández-Cruz L, Cosa R, Blanco L, López-Boado MA, Astudillo E.
Pancreatogastrostomy with gastric partition after pylorus-preserving pancreatoduodenectomy versus conventional pancreatojejunostomy: a prospective randomized study. Ann Surg. 2008 Dec;248(6):930-8.

11. Hong TH, Youn YC, You YK, Kim DG. An easy and secure pancreaticogastrostomy after pancreaticoduodenectomy: transpancreatic suture with a buttress method through an anterior gastrotomy. J Korean Surg Soc. 2011 Nov;81(5):332-8.

12. Mimatsu K, Oida T, Kano H, Kawasaki A, Fukino N, Kida K, et al. Protection of major vessels and pancreaticogastrostomy using the falciform ligament and greater omentum for preventing pancreatic fistula in soft pancreatic texture after pancreaticoduodenectomy. Hepatogastroenterology. 2011 Sep-0ct;58(110-111):1782-6.

13. Oida T, Mimastu K, Kawasaki A, Kuboi Y, Kano H, Amano S. Toward zero pancreatic leakage after pancreaticoduodenectomy for soft pancreas in low-volume pancreatic surgery centers. Hepatogastroenterology. 2009 May-Jun;56(91-92):886-90.

14. Peng SY, Wang JW, Hong de F, Liu YB, Wang YF. Binding pancreaticoenteric anastomosis: from binding pancreaticojejunostomy to binding pancreaticogastrostomy. Updates Surg. 2011 Jun;63(2):69-74.

15. Rosso E, Lopez P, Roedlisch MN, Narita M, Oussoultzoglou E, Bachellier P. Double omental flap reduced perianastomotic collections and relaparotomy rates after pancreaticoduodenectomy with pancreaticogastrostomy. World J Surg. 2012 Jul;36(7):1672-8.

16. Takao S, Shinchi H. Pancreaticogastrostomy: a pancreas-transfixing method with duct-to-mucosa anastomosis (with video). J Hepatobiliary Pancreat Sci. 2012 Mar;19(2):131-4.

17. Wellner U, Makowiec F, Fischer E, Hopt UT, Keck T. Reduced postoperative pancreatic fistula rate after pancreatogastrostomy versus pancreatico-jejunostomy. J Gastrointest Surg. 2009 Apr:13(4):745-51.

18. Zhu YP, Zhou W, Zhang NY, Pan JH, Li B, Wang XF. A new technique of mesh-reinforced pancreaticogastrostomy: report of 13 initial cases. J Laparoendosc Adv Surg Tech A. 2013 Jul;23(7):617-20.

19. Fingerhut $A$, Vassiliu $P$, Dervenis $C$, Alexakis N, Leandros E. What is in a word: Pancreatoduodenectomy or pancreaticoduodenectomy? Surgery. 2007 Sep;142(3):428-9.

20. Bartoli FG, Arnone GB, Ravera G, Bachi V. Pancreatic fistula and relative mortality in malignant disease after pancreaticoduodenectomy. Review and statistical meta-analysis regarding 15 years of literature. Anticancer Res. 1991 Sep-0ct;11(5):1831-48.

21. Wente MN, Shrikhande SV, Müller MW, Diener MK, Seiler CM, Friess $\mathrm{H}$, et al. Pancreaticojejunostomy versus pancreaticogastrostomy: systematic review and meta-analysis. Am J Surg. 2007 Feb;193(2):17183

22. Yeo CJ, Cameron JL, Maher MM, Sauter PK, Zahurak ML, Talamini MA, et al. A prospective randomized trial of pancreaticogastrostomy versus pancreaticojejunostomy after pancreaticoduodenectomy. Ann Surg. 1995 0ct;222(4):580-8; discussion 588-92.

23. Bassi C, Falconi M, Molinari E, Salvia R, Butturini G, Sartori N, et al. Reconstruction by pancreaticojejunostomy versus pancreaticogastrostomy following pancreatectomy: results of a comparative study. Ann Surg. 2005 Dec;242(6):767-71, discussion 771-3.

24. Duffas JP, Suc B, Msika S, Fourtanier G, Muscari F, Hay JM, et al. A controlled randomized multicenter trial of pancreatogastrostomy or pancreatojejunostomy after pancreatoduodenectomy. Am J Surg. 2005 Jun; 189(6):720-9.

25. Bassi C, Dervenis C, Butturini G, Fingerhut A, Yeo C, Izbicki J, et al. Postoperative pancreatic fistula: an international study group (ISGPF) definition. Surgery. 2005 Jul;138(1):8-13.

26. Wellner UF, Sick 0, Olschewski M, Adam U, Hopt UT, Keck T. Randomized controlled single-center trial comparing pancreatogastrostomy versus pancreaticojejunostomy after partial pancreatoduodenectomy. J Gastrointest Surg. 2012 Sep;16(9):1686-95

27. Figueras J, Sabater L, Planellas P, Muñoz-Forner E, Lopez-Ben S, Falgueras $\mathrm{L}$, et al. Randomized clinical trial of pancreaticogastrostomy versus pancreaticojejunostomy on the rate and severity of pancreatic fistula after pancreaticoduodenectomy. Br J Surg. $2013 \mathrm{Nov}$; 100(12):1597-605. doi: 10.1002/bjs.9252.

28. El Nakeeb A, Hamdy E, Sultan AM, Salah T, Askr W, Ezzat H, et al. Isolated Roux loop pancreaticojejunostomy versus pancreaticogastrostomy after pancreaticoduodenectomy: a prospective randomized study. HPB (Oxford). 2014 Aug;16(8):713-22. 
29. Topal B, Fieuws S, Aerts R, Weerts J, Feryn T, Roeyen G, et al. Pancreaticojejunostomy versus pancreaticogastrostomy reconstruction after pancreaticoduodenectomy for pancreatic or periampullary tumours: a multicentre randomised trial. Lancet Oncol. 2013 Jun;14(7):655-62.

30. Keck T, Wellner UF, Bahra M, Klein F, Sick O, Niedergethmann M, et al. Pancreatogastrostomy versus pancreatojejunostomy for RECOnstruction after PANCreatoduodenectomy (RECOPANC, DRKS 00000767): perioperative and long-term results of a multicenter randomized controlled trial. Ann Surg. 2016 Mar;263(3):440-9.

31. Chen Z, Song X, Yang D, Li Y, Xu K, He Y. Pancreaticogastrostomy versus pancreaticojejunostomy after pancreaticoduodenectomy: a meta-analysis of randomized control trials. Eur J Surg Oncol. 2014 0ct;40(10):1177-85.

32. Clerveus M, Morandeira-Rivas A, Picazo-Yeste J, Moreno-Sanz C. Pancreaticogastrostomy versus pancreaticojejunostomy after pancreaticoduodenectomy: a systematic review and meta-analysis of randomized controlled trials.. J Gastrointest Surg. 2014 Sep;18(9): 1693-704.

33. Hallet J, Zih FS, Deobald RG, Scheer AS, Law CH, Coburn NG, et al. Author information The impact of pancreaticojejunostomy versus pancreatico-gastrostomy reconstruction on pancreatic fistula after pancreatico-duodenectomy: meta-analysis of randomized controlled trials. HPB (0xford). 2015 Feb;17(2):113-22.

34. Liu FB, Chen JM, Geng W, Xie SX, Zhao YJ, Yu LQ, et al. Pancreaticogastrostomy is associated with significantly less pancreatic fistula than pancreaticojejunostomy reconstruction after pancreatico-duodenectomy: a meta-analysis of seven randomized controlled trials. HPB (0xford). 2015 Feb;17(2):123-30.

35. Ma S, Li Q, Dai W, Pan F. Pancreaticogastrostomy versus pancreaticojejunostomy. J Surg Res. 2014 Nov;192(1):68-75.

36. Menahem B, Guittet L, Mulliri A, Alves A, Lubrano J. Pancreaticogastrostomy is superior to pancreaticojejunostomy for prevention of pancreatic fistula after pancreaticoduodenectomy: an updated metaanalysis of randomized controlled trials. Ann Surg. 2015 May;261(5):882-7.

37. Xiong JJ, Tan CL, Szatmary P, Huang W, Ke NW, Hu WM, et al. Metaanalysis of pancreaticogastrostomy versus pancreaticojejunostomy after pancreaticoduodenectomy. Br J Surg. 2014 Sep;101(10):1196208.

38. Zhang X, Ma L, Gao X, Bao H, Liu P, Aziz A, et al. Pancreaticogastrostomy versus pancreaticojejunostomy reconstruction after pancreaticoduodenectomy: a meta-analysis of randomized controlled trials. Surg Today. 2015 May;45(5):585-94.

39. Wente MN, Veit JA, Bassi C, Dervenis C, Fingerhut A, Gouma DJ, et al. Postpancreatectomy hemorrhage (PPH): an International Study Group of Pancreatic Surgery (ISGPS) definition. Surgery. 2007 Jul;142(1): 20-5.

40. Niedergethmann M, Dusch N, Widyaningsih R, Weiss C, Kienle P, Post S. Risk-adapted anastomosis for partial pancreaticoduodenectomy reduces the risk of pancreatic fistula: a pilot study. World J Surg. 2010 Jul; 34(7):1579-86.

41. Wellner UF, Kulemann B, Lapshyn H, Hoeppner J, Sick O, Makowiec F, et al. Postpancreatectomy hemorrhage--incidence, treatment, and risk factors in over 1,000 pancreatic resections. J Gastrointest Surg. 2014 Mar;18(3):464-75.

42. Standop J, Schäfer N, Overhaus M, Schmitz V, Ladwein L, Hirner A, et al Endoscopic management of anastomotic hemorrhage from pancreato-gastrostomy. Surg Endosc. 2009 Sep;23(9):2005-10.

43. Eckardt AJ, Klein F, Adler A, Veltzke-Schlieker W, Warnick P, Bahra M, et al. Management and outcomes of haemorrhage after pancreatogastrostomy versus pancreatojejunostomy. Br J Surg. 2011 Nov; 98(11):1599-607.

44. Bachellier P, Oussoultzoglou E, Rosso E, Scurtu R, Lucescu I, Oshita $A$, et al. Pancreatogastrostomy as a salvage procedure to treat severe post-operative pancreatic fistula after pancreatoduodenectomy. Arch Surg. 2008 0ct;143(10):966-70; discussion 971.

45. Govil S. Salvage pancreaticogastrostomy for pancreatic fistulae after pancreaticoduodenectomy. Indian J Gastroenterol. 2012 Sep;31(5): 263-6.

46. Amano H, Takada T, Ammori BJ, Yasuda H, Yoshida M, Uchida T, et al.
Pancreatic duct patency after pancreaticogastrostomy: long-term follow-up study. Hepatogastroenterology. 1998 Nov-Dec;45(24): 2382-7.

47. Kurosaki I, Hatakeyama K, Kobayashi T, Nihei KE. Pancreaticogastrostomy: unreliable long-term pancreatic duct patency. Hepatogastroenterology. 2003 Mar-Apr;50(50):545-9.

48. Lemaire E, O'Toole D, Sauvanet A, Hammel P, Belghiti J, Ruszniewski P. Functional and morphological changes in the pancreatic remnant following pancreaticoduodenectomy with pancreaticogastric anastomosis. Br J Surg. 2000 Apr;87(4):434-8.

49. Murakami Y, Uemura K, Hayashidani Y, Sudo T, Hashimoto Y, Ohge H, et al. Long-term pancreatic endocrine function following pancreatoduodenectomy with pancreaticogastrostomy. J Surg Oncol. 2008 May 1;97(6):519-22.

50. Nakamura H, Murakami Y, Uemura K, Hayashidani Y, Sudo T, Ohge H, et al. Predictive factors for exocrine pancreatic insufficiency after pancreatoduodenectomy with pancreaticogastrostomy. J Gastrointest Surg. 2009 Jul;13(7):1321-7.

51. Pessaux P, Aube C, Lebigot J, Tuech JJ, Regenet N, Kapel N, et al. Permeability and functionality of pancreaticogastrostomy after pancreaticoduodenectomy with dynamic magnetic resonance pancreatography after secretin stimulation. J Am Coll Surg. 2002 Apr;194(4):454-62.

52. Shyr YM, Su CH, Wu CW, Lui WY. Gastric pH and amylase and safety for non-stented pancreaticogastrostomy. Hepatogastroenterology. 2002 Nov-Dec;49(48):1747-50.

53. Sikkens EC, Cahen DL, de Wit J, Looman CW, van Eijck C, Bruno MJ. A prospective assessment of the natural course of the exocrine pancreatic function in patients with a pancreatic head tumor. J Clin Gastroenterol. 2014 May-Jun;48(5):e43-6.

54. Sikkens EC, Cahen DL, de Wit J, Looman CW, van Eijck C, Bruno MJ. Prospective assessment of the influence of pancreatic cancer resection on exocrine pancreatic function. $\mathrm{Br} \mathrm{J}$ Surg. 2014 Jan;101(2):109-13.

55. Fang WL, Su CH, Shyr YM, Chen TH, Lee RC, Tai LC, et al. Functional and morphological changes in pancreatic remnant after pancreaticoduodenectomy. Pancreas. 2007 Nov;35(4):361-5.

56. Ishikawa O, Ohigashi H, Eguchi H, Yokoyama S, Yamada T, Takachi K, et al. Long-term follow-up of glucose tolerance function after pancreaticoduodenectomy: comparison between pancreaticogastrostomy and pancreaticojejunostomy. Surgery. 2004 Sep;136(3): 617-23.

57. Ma JP, Chen CQ, Cai SR, Shi HP, He YL, Zhan WH. Comparison of nutritional status between pancreaticojejunostomy and pancreaticogastrostomy following pancreaticoduodenectomy. Zhonghua Wei Chang Wai Ke Za Zhi. 2012 May;15(5):457-9. Chinese

58. Morera-Ocon FJ, Sabater-Orti L, Muñoz-Forner E, Pérez-Griera J, Ortega-Serrano J. Considerations on pancreatic exocrine function after pancreaticoduodenectomy. World J Gastrointest Oncol. 2014 Sep 15;6(9):325-9.

59. Schmidt U, Simunec D, Piso P, Klempnauer J, Schlitt HJ. Quality of life and functional long-term outcome after partial pancreatoduodenectomy: pancreatogastrostomy versus pancreatojejunostomy. Ann Surg Oncol. 2005 Jun;12(6):467-72.

60. Takada T, Yasuda H, Uchiyama K, Hasegawa H, Misu Y, Iwagaki T. Pancreatic enzyme activity after a pylorus-preserving pancreaticoduodenectomy reconstructed with pancreaticogastrostomy. Pancreas. 1995 0ct;11(3):276-82.

61. Hirono S, Murakami Y, Tani M, et al. Identification of Risk Factors for Pancreatic Exocrine Insufficiency After Pancreaticoduodenectomy Using a (13)C-Labeled Mixed Triglyceride Breath Test. World J Surg. 2014;

62. Jang JY, Kim SW, Park SJ, Park YH. Comparison of the functional outcome after pylorus-preserving pancreatoduodenectomy: pancreatogastrostomy and pancreatojejunostomy. World J Surg. 2002 Mar; 26(3):366-71.

63. Rault A, SaCunha A, Klopfenstein D, Larroudé D, Epoy FN, Collet D, Masson B. Pancreaticojejunal anastomosis is preferable to pancreaticogastrostomy after pancreaticoduodenectomy for longterm outcomes of pancreatic exocrine function. J Am Coll Surg. 2005 Aug; 201(2):239-44. 
64. Yamaguchi K, Tanaka M, Chijiiwa K, Nagakawa T, Imamura M, Takada T. Early and late complications of pylorus-preserving pancreatoduodenectomy in Japan 1998. J Hepatobiliary Pancreat Surg. 1999; 6(3):303-11.

65. Miyakawa S, Niwamoto N, Horiguchi A, Hanai T, Mizuno K, Ishihara $\mathrm{S}$, et al. Fat absorption after pylorus-preserving pancreatoduodenectomy reconstructed with Billroth II pancreaticojejunostomy or Billroth I pancreaticogastrostomy. Hepatogastroenterology. 2000 Jan-Feb;47(31): 264-8.

66. Le Blanc-Louvry I, Ducrotté P, Peillon C, Testart J, Denis P, Michot F, et al. Upper jejunal motility after pancreatoduodenectomy according to the type of anastomosis, pancreaticojejunal or pancreaticogastric. J Am Coll Surg. 1999 Mar;188(3):261-70.

67. Konishi M1, Ryu M, Kinoshita T, Inoue K. Pathophysiology after pylorus-preserving pancreatoduodenectomy: a comparative study of pancreato-gastrostomy and pancreatojejunostomy. Hepatogastroenterology. 1999 Mar-Apr;46(26):1181-6.

68. Fernández-Cruz L1, López-Boado MA, Ferrer J. Repeated pancreatectomy after pancreato-duodenectomy for a intraductal papillary mucinous tumour: advantage of pancreatico-gastrostomy with a gastric partition. HPB (Oxford). 2012 Feb;14(2):132-5.

69. Gigot JF, Deprez P, Sempoux C, Descamps C, Metairie S, Glineur D, et al. Surgical management of intraductal papillary mucinous tumors of the pancreas: the role of routine frozen section of the surgical margin, intra-operative endoscopic staged biopsies of the Wirsung duct, and pancreaticogastric anastomosis. Arch Surg. 2001 Nov;136(11):125662.
70. Tomimaru Y, Ishikawa 0, Ohigashi H, Eguchi H, Yamada T, Sasaki Y, et al. Advantage of pancreaticogastrostomy in detecting recurrent intraductal papillary mucinous carcinoma in the remnant pancreas: a case of successful re-resection after pancreaticoduodenectomy. J Surg Oncol. 2006 May 1;93(6):511-5.

71. lacono C, Verlato G, Ruzzenente A, Campagnaro T, Bacchelli C, Valdegamberi A, et al. Systematic review of central pancreatectomy and meta-analysis of central versus distal pancreatectomy. Br J Surg. 2013 Jun;100(7):873-85. doi: 10.1002/bjs.9136.

72. Machado MA, Surjan RC, Epstein MG, Makdissi FF. Laparoscopic central pancreatectomy: a review of 51 cases. Surg Laparosc Endosc Percutan Tech. 2013 Dec;23(6):486-90.

73. Diener MK, Seiler CM, Rossion I, Kleeff J, Glanemann M, Butturini G, et al. Efficacy of stapler versus hand-sewn closure after distal pancreatectomy (DISPACT): a randomised, controlled multicentre trial. Lancet. 2011 Apr 30;377(9776):1514-22.

74. Sudo T, Murakami $\mathrm{Y}$, Uemura $\mathrm{K}$, Hayashidani $\mathrm{Y}$, Hashimoto $\mathrm{Y}$, Nakashima A, et al. Distal pancreatectomy with duct-to-mucosa pancreaticogastro-stomy: a novel technique for preventing postoperative pancreatic fistula. Am J Surg. 2011 Jul;202(1):77-81.

75. Yanagimoto H, Satoi S, Toyokawa H, Yamamoto T, Hirooka S, Yamao J, et al. Pancreaticogastro-stomy following distal pancreatectomy prevents pancreatic fistula-related complications. J Hepatobiliary Pancreat Sci. 2014 Jul;21(7):473-8.

76. Standop J, Overhaus M, Schaefer N, Decker D, Wolff M, Hirner A, et al. Pancreatogastrostomy after pancreatoduodenectomy: a safe, feasible reconstruction method? World J Surg. 2005 Apr;29(4):505-12. 